Research Article

\title{
Effects of Three Tillage Systems on Physical Properties of a Sandy Loam Soil
}

\author{
Khaoula Abrougui $^{\dot{\mathrm{A}}}$, Hassina Hafida Boukhalfa ${ }^{\dot{\mathrm{B}}}$, Anis Elaoud ${ }^{\dot{\mathrm{A}}, \dot{\mathrm{C}}}$, Jean Noel Louvet ${ }^{\dot{\mathrm{D}}}$, Marie France Destain ${ }^{\dot{\mathrm{D}}}$ and $^{\text {Sayed }}$ \\ Chehaibi $^{\dot{A}}$ \\ ${ }^{\dot{A}}$ Department of Horticultural Systems Engineering, Higher Institute of Agronomy 4042 Sousse (Tunisie) \\ ${ }^{\dot{B}}$ Department of agronomy, University Mohamed Khider- Biskra, Biskra, (Algeria) \\ ${ }^{\mathrm{C}}$ Water Researches and Technologies Centre of Borj-Cedria, 8020 Soliman( Tunisie) \\ ${ }^{\mathrm{D}}$ Unity of Mechanics and Construction, Gembloux Agro-Bio Tech, University of Liège, 5030 Gembloux (Belgium)
}

Accepted 01 October 2014, Available online 20 October 2014, Vol.4, No.6 (October 2014)

\begin{abstract}
To evaluate the impact of tillage systems on soil environment, it is necessary to quantify the modifications to the soil structure. Three different techniques were compared: minimum tillage with discs harrow, medium tillage with discs plow and conventional deep tillage with mouldboard plowing. Tests were carried out over a sandy loam soil in the Higher Institute of Agronomy of ChottMeriem (Tunisia). Tillage was followed by a first resumption 10 days after and a second one 20 days after. The studied parameters were measured at initial state and after tillage over time. Soil structure was characterized by its resistance to penetration and bulk density. Crumbling index was also evaluated by the method of clods sieving. In soil tilled by conventional system, soil resistance and bulk density increased for a depth of $30 \mathrm{~cm}$. In contrast, tillage with discs plow showed lower values of these parameters in both the surface layer (10 cm) and the plowing depth $(20 \mathrm{~cm})$. Minimum tillage system, showed the best values of soil resistance and bulk density than the other systems and a better improvement in soil crumbling index.
\end{abstract}

Keywords: soil structure, tillage systems, reduced tillage, soil resistance, bulk density, crumbling index.

\section{Introduction}

Tillage aims to condition soil most favorable for cultivation. All vegetables are concerned with quality of soil structure and thus with good tillage. A well tilled soil is a not compacted soil in depth $(20 / 30 \mathrm{~cm})$ and very soft in surface. The basic technique of tillage is plowing. Plowing is a tillage operation which consists in returning the soil so that the lower part of soil is brought to the surface. After plowing, it is often necessary to refine the soil surface by a resumption work of the soil (Abrougui et al., 2012a). Structure of the tilled layer of cultivated soil changes with times because of tillage itself, compaction under traffic and as a result of natural processes (root growth, faunal activity and weather). Mechanized cultivation produces stresses within the soil, which cause fragmentation, compaction and displacement of soil. The combined effects of these processes alter the special arrangement, size and shape of clods and aggregates, and consequently, volume of pore spaces inside and between these units (Dexter, 1988). These stresses affect soil volumes, the sizes and location of which vary from one part of the field to another (Manichon, 1988). Ceasing to plough can reduce costs and environmental damage like erosion (Soane and van Ouwerkerk, 1994) but ploughing is still widely practiced in many countries. The main reason is that mouldboardploughing creates a desirable

*Corresponding author: KhaoulaAbrougui tilth, controls weeds, and buries fertilizers and residues of the preceding crops. It is therefore important to study the effect of tillage systems on soil structure. The changes depend, for a given texture, on the soil conditions (structure and water content) when the mechanical stress is applied, and on the characteristics of the equipments (Koolen, 1994). Estradeet al., (2000), described a new approach to modeling soil structure that takes into account the special variation in structure of the tilled layer at a field scale. It is based on the simulation of the changes over time in the percentage of compacted soil within the tilled layer in mechanized cropping, where the main factors responsible for change are tillage and traffic. Estradeet al., (2004), studied the morphological characterization of soil structure in tilled fields from a diagnosis method to the modeling of structural changes over time. The need to reduce the environmental impact of agricultural activities and to control soil structure degradation is one of the main aims of land management (Pagliaiet al., 2004). They evaluated the effects of different types of management practices, namely tillage and manure application, on soil structural characteristics. In fact, the main consequence of long-term intensive cultivation is the degradation of soil structure, which can reduce the effect of chemical fertilizers. As soil erosion increases, solid soil particles and nutrients can be transported with the consequent risk of surface water pollution. Moreover, the resulting soil porosity conditions 
are often unfavorable to crop growth (Pagliaiet al., 1998). Water scarcity is the major problem limiting crop productivity in semi-arid Mbeere district, but little attention has been given to the soil management practices that can address this problem for increasing crop productivity (Gicheruet al., 2004). Sandy loam to clay loam soils is the most susceptible to surface sealing and crusting (Courty, 1985). The soils are moderately deep, well drained brown to dark reddish brown, sandy loam in the topsoil tending to sandy clay at the subsoil. They tend to compact when dry but are friable when wet (FAO, 1997). The moisture increases down the profile. This is influenced by the clay increase down the profile. Tillage practices involving annual ploughing without other soil management practices and which have been widely practiced in the lower semi-arid Mbere, are increasingly being recognized to have deleterious effects on soil conditions (Briggs et al., 1998). This paper describes a new comparison between three tillage systems that takes into account the changes in the structure of the tilled layer at a plot scale. It is based on the changes over time in cone resistance to penetration, bulk density and soil fragmentation, where the main factors responsible for change are tillage system, working depth and natural conditions.

\section{Materials and Methods}

The study was carried out at the Higher Institute of Agronomy of Chott Meriem (Tunisia).The trials were conducted on a $1.7 \%$ slope sandy loam soil (Table 1) using a standard two-wheel-drive tractor equipped with single rear tires and having a total weight of $2,910 \mathrm{~kg}(1,715 \mathrm{~kg}$ on the rear axle) and a power of $59 \mathrm{~kW}$.To study the influence of tillage system on soil physical properties, soil resistance to penetration, bulk density and soil crumbling index were studied and we assess the evolution of these parameters over time. The site had been used for a 2 years tillage study. Data were analyzed using the statistic software (SPSS). Tillage treatments and replicates were identified as the main effects. SNK test at $* \mathrm{P} \leq 0.05$ was used to distinguish treatment differences.

Table 1 Medium grain size

\begin{tabular}{cccc}
\hline Depth $(\mathrm{cm})$ & Clay $(\%)$ & Loam $(\%)$ & Sand $(\%)$ \\
\hline $0-20$ & 8 & 66.6 & 25.3 \\
$20-40$ & 9.7 & 57.1 & 33.1 \\
\hline
\end{tabular}

\subsection{Experimental conditions}

The experimental layout includes a studied factor: soil tillage under three different systems T1, T2 and T3 (Figure 2) and three measured variables: soil resistance to penetration (Billot, 1989), dry bulk density and superficial crumbling index. A resumption of tillage for the three treatments is achieved by two passages of disc harrow (offset). The statistical design was a randomized complete block with three replications (Figure 1).

Treatment $1=\mathrm{T} 1$ : reduced or minimum tillage using a disc harrow (Offset) at a maximum depth of $10 \mathrm{~cm}$ (Figure $2 \mathrm{~A})+2$ tillage resumptions spaced of 10 days, using a disc harrow;
Treatment $2=\mathrm{T} 2$ : medium tillage with disc plowing at a maximum depth of $20 \mathrm{~cm}$ (Figure 2B) +2 tillage resumptions spaced of 10 days, using a disc harrow;

Treatment $3=\mathrm{T} 3$ : conventional deep tillage with mouldboard plowing at a maximum depth of $30 \mathrm{~cm}$ (Figure 2C) +2 tillage resumptions spaced of 10 days, using a disc harrow.Samples (presented by circles in figure 1) were collected from within each tilled plot not under the wheels passages at different dates spaced of 60 days, to measure suggested physical indicators of soil quality.

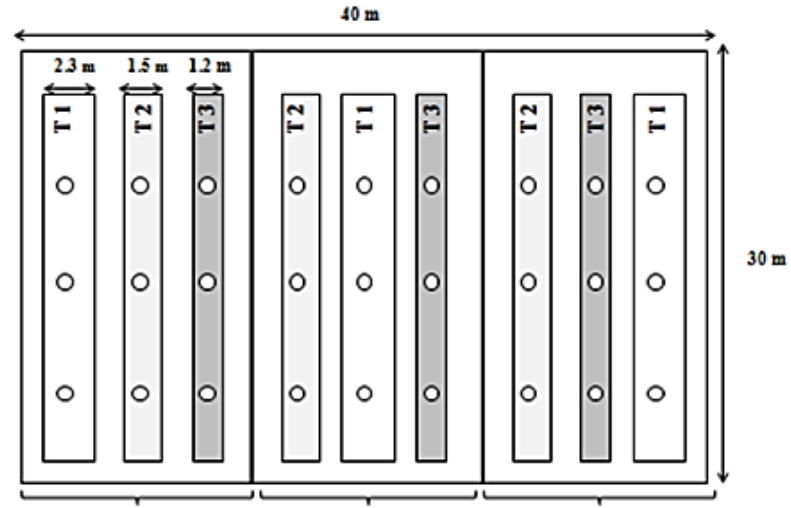

$$
\begin{array}{lll}
\text { Block } 1 \quad \text { Block } 2 \quad \text { Block } 3
\end{array}
$$

Figure 1Experimental layout

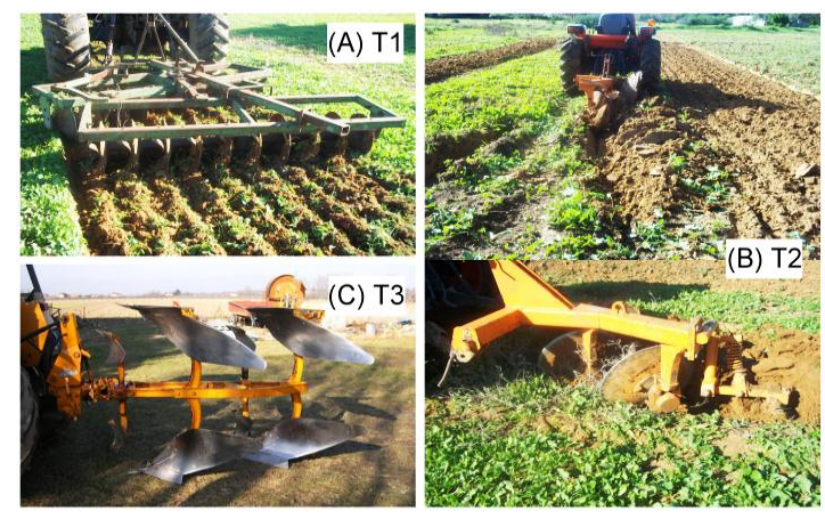

Figure 2 Soil tillage tools: (A) T1 disc harrow used in treatment 1; (B) T2 two disc plow used in treatment 2; (C) T3 moldboard plow usedin treatment 3

\subsection{Characterization and measurement modalities}

The evaluation of soil compaction is based on the determination of soil resistance to penetration (Vitlox and Loyer, 2002). It is a non destructive method considering the importance of the experimental site. Furthermore, this method is more sensitive than the bulk density to characterizethe differences in soil compaction (Allen and Musick, 1997). The used penetrometer is of electronic type, also called penetrologger. Coupled to a recorder, this device allows the storage and immediate processing of data. It consists of a force sensor, a recorder, a drill pipe, a cone, and an ultrasonic depth gauge. The apparatus is run by two ergonomic handles for easy access to various commands. The application of equal pressure on both handles pushes the cone vertically into the soil. A mechanism of integrated measuring allows recording the penetration resistance encountered during the phase of 
insertion of the cone (Abrougui et al., 2012b).The measurements of soil resistance to penetration were done each $10 \mathrm{~cm}$ to a depth of $50 \mathrm{~cm}$. Soil water content was measured jointly and was determined by drying the soil samples at $105^{\circ} \mathrm{C}$ (Keller et al., 2007). Soil density $\left(\mathrm{g} / \mathrm{cm}^{3}\right)$ was measured by a soil cylindrical core (diameter $=5 \mathrm{~cm}$, height $=5 \mathrm{~cm}$ ) taken with a cylinder densimeter, the sample was collected every $10 \mathrm{~cm}$, at a depth of $30 \mathrm{~cm}$. We then obtained the dry mass of the sample after drying in a stove at a temperature of $105^{\circ} \mathrm{C}$ for 24 hours (Yoro and Godo, 1990).

Regarding the soil crumbling index, measurement of the seed bed crumbling by clods sieving, determines the size of the seed bed components. This factor plays a role in the functioning of the planting organs of the sowing machine and determines a more or less rapid emergence of culture (Lajoux, 2003).

Samples are collected with a garden trowel in representative areas using a wide range with a flat bottom (20 $\mathrm{cm}$ of width, $30 \mathrm{~cm}$ of length and $10 \mathrm{~cm}$ of height). The collected soil were air-dried and sieved (manually) through sieves with square holes. We put apart the refusal of the various sieves and we weigh clods belonging to each of classes well separated. To calculate the crumbling index, each class of the clods is assigned a coefficient Iei. Value (without unity) of the global crumbling index Ie is then determined by the following expression:

\section{$\mathrm{Ie}=\Sigma \mathrm{Mi} * \mathrm{Iei} / \mathrm{Mt}$}

$\Sigma \mathrm{Mi} *$ Iei $=$ sum of products of the masses Mi $(\mathrm{kg})$ for each class with the corresponding values of the coefficient Iei;

$\mathrm{Mt}=$ total mass of the sample $(\mathrm{kg})$.

The crumbling index of the studied plot will be given by the average of three values corresponding to the collected samples. More it is close to 1 , more the seedbed will be crumbled.

The initial state of the parcel before tillage is characterized by homogeneous state with an average soil resistance to penetration of $3.63 \mathrm{MPa}$, an average bulk density of $2.3 \mathrm{~g} / \mathrm{cm}^{3}$ and a water content of $7.67 \%$ on the horizon 0-30 $\mathrm{cm}$.

\section{Results and discussion}

\subsection{Soil resistance to penetration}

Examination of average penetrometric profiles (Figure 3) of the different treatments compared to the initial state reveal a decrease in soil resistance after passage of the different tools as a function of carried monitoring. The average profiles of the three treatments have an increasing sit from the soil surface to the concerned working depth, then a pace close to that of the initial state which characterizes the not worked area. This shows the effect of the studied tillage system on soil resistance to penetration. In comparison with continuous conventional ploughing, alternative tillage systems, like disc plowing and minimum tillage, improved soil structural state by decreasing its resistance to penetration. Soil resistance to penetration was lower under disc plowing and minimum tillage treatment than in conventional ploughing treatment. The occurrence of lower soil resistance under disc plowing and minimum tillage could be related to an increase of soil water content (Figure 4) and consequently, to an increase of available water for plants (Pagliai et al., 1998).Measurements were performed to a depth of $50 \mathrm{~cm}$ at the initial state, immediately after the second tillage resumption and a monitor of the soil structural state was carried out at different dates spaced of 60 days. In the surface layer $(0-$ $10 \mathrm{~cm}$ ) of conventionally tilled soil (Treatment 3), soil resistance to penetration was significantly greater than in soil under minimum tillage (Treatment 1 ) or disc plowing (Treatment 2). The minimum tillage showed the lowest values of soil resistance. It is important to note that the highest value of soil resistance to penetration was found in the 40-50 cmlayer of conventionally tilled soil. Angers et al., (1993) showed that stability of soil surface structure is generally greater in fields under direct seeding and culture on ridges than in conventional tillage (plowing). The main possible reasons for this are that tillage reduced the amount of surface organic matter and biological activity is lower in soil surface after plowing, the mechanical action of tillage breaks aggregates forming soil structure and the abundance of earthworms in reduced tillage or direct seeding encourages the development of pores which improves soil structure.Moreover, reduced tillage and direct seeding have the advantage of requiring fewer passages of the machinery when the soil is wetter in autumn and spring and not lead to plow pans formation.Indeed, figure 3 shows that soil resistance beyond the plowed layer under conventional tillage is higher than under disc plowing and reduced tillage. Soil resistance is 3.1, 2.4 and $2 \mathrm{MPa}$ under conventional deep tillage, discs plowing and reduced tillage respectively, at $40 \mathrm{~cm}$ of depth at the first measurement 60 days after tillage. Under reduced tillage, aggregates stability is often similar to that observed under conventional plowing because of the destruction of aggregates under the action of tillage equipment but this practice promotes the accumulation of organic matter in surface for reduced tillage. However, in depth, the beneficial effects of disc harrow (offset) occur. Contrary to plowing, the tractor movement in surface leads to soil compaction at the worked horizon. This compaction could eventually be stopped by the mechanical action of tillage equipment.In the case of conventional tillage, the fact that the tractor wheel is at the bottom of the furrow promotes soil compaction beyond the plow layer. The action of tillage tools cannotlimit this compaction which results in a more massive soil with low porosity. These operations that improve soil structure, such as zero tillage, provided some protection against soil compaction. Indeed, soil resistance to penetration decreases from one measurement date to another compared to the initial state and for the three tillage systems. At the fourth date, values of soil resistance increase having a similar pace to that of theinitial state, so the soil tends to be compacted again which also may be due to the decrease in water content. The lowest values of soil resistance are presented in figure 3 for reduced tillage 
system. The improvement of soil properties and, consequently, the profile by reducing tillage, occurs gradually over several years (CRAAQ, 2011).
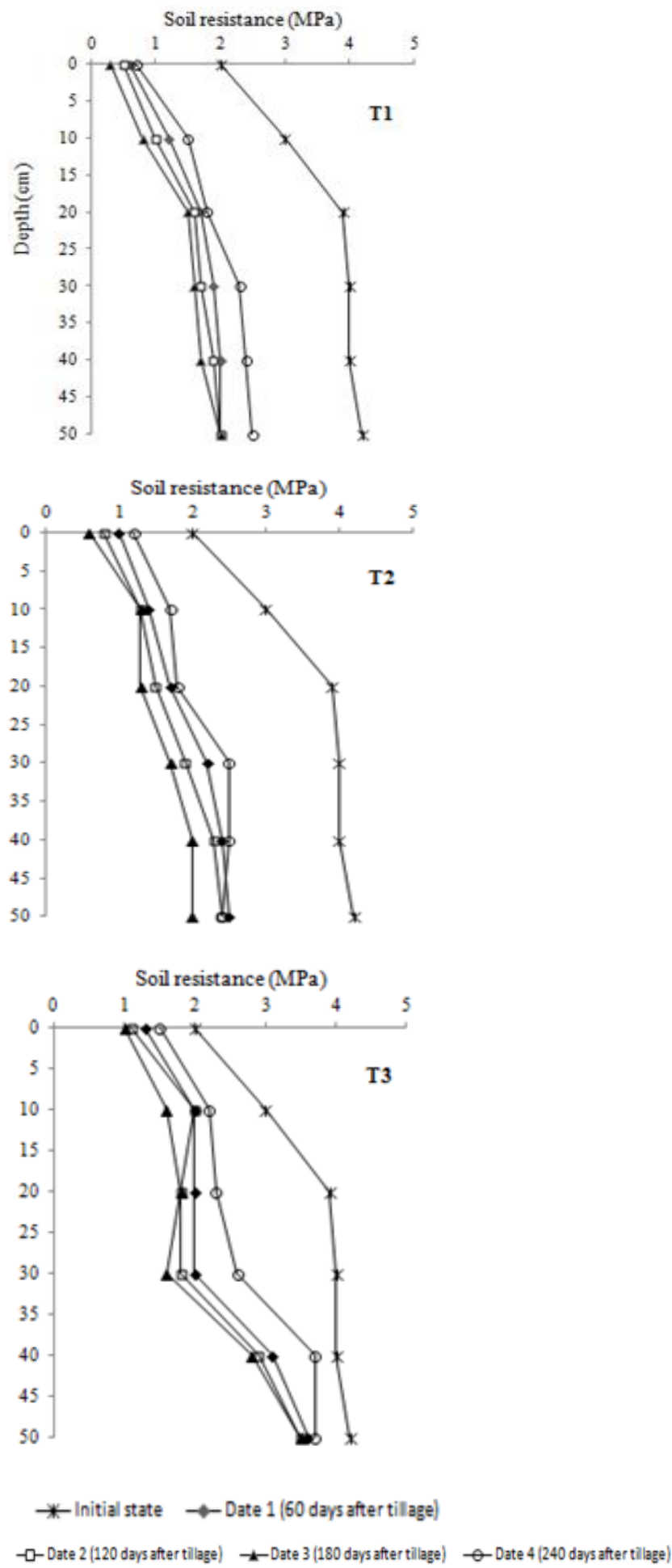

Figure 3Effect of conventional (T3), medium (T2) and minimum (T1) tillage on soil resistance to penetration

Statistical analyses of the data at $* \mathrm{P}<0.05$ show significant effects of treatment, date of measurement and depth on the soil resistance (Table 2). Average soil resistance at $0-50 \mathrm{~cm}$ and for all measurement dates, significantly deferred for the three studied tillage systems and the different letters indicate different classes of soil resistance (Table 3). The highest average corresponds to the initialstate whereas the lowest occurs following minimum tillage (Treatment 1). Soil resistance also significantly differs from one depth to another and increases with increasing depth.

Table 2 ANOVA results for the soil resistance to penetration data

\begin{tabular}{ccc}
\hline Source of variation & D.F. & M.S. \\
\hline Treatment & 3 & $56.014^{* *}$ \\
Date & 3 & $2.34^{* *}$ \\
Depth & 5 & $23.05^{* *}$ \\
Treatment*Date & 9 & $0.285^{* *}$ \\
Error & 192 & 0.086 \\
\hline \multirow{2}{*}{$*$ : significant at the 5\% level. }
\end{tabular}

Table 3 Average values of soil resistance to penetration

\begin{tabular}{cc}
\hline Treatment & Soil resistance \\
\hline Initial state & $3.51 \mathrm{~d}$ \\
T 1 & $1.54 \mathrm{a}$ \\
T 2 & $1.76 \mathrm{~b}$ \\
T 3 & $2.32 \mathrm{c}$ \\
\hline
\end{tabular}

\subsection{Bulk density}

Examination of average bulk densities for the three treatments compared to initial state and the first measurement date, show a decrease in bulk density, therefore increasing soil porosity under the three treatments (Figure 5). At the initial state of untilled soil, bulk density was $2.2,2.3$ and $2.5 \mathrm{~g} / \mathrm{cm}^{3}$ at 10,20 and 30 $\mathrm{cm}$ of depth respectively. Comparing values of dry bulk density at various depths, showed significant differences between T1 and T3 treatments on soil depth between 10 and $30 \mathrm{~cm}$. Beyond the tilled layer, T2 and T3 show a dense horizon characterizing a compacted soil in depth following passages of the set tractor-tool. Soil compaction often alters soil properties (Strudleyet al., 2008), resulting changes in plant available water (Gomez et al., 2002). In a study of Ishaqet al. (2001), subsoil compaction reduced both water and nutriment use efficiencies of wheat grown in sandy clay loam soil by $38 \%$ in first year and $9 \%$ in the second year. Tillage practices used during land preparation for crop production could also induce soil compaction due to heavy load of vehicles which result in breaking of soil structure and reducing macropores volume (Arachchi, 2009; Defossezet al., 2003). The moldboard plow is the most flexible tool in relation to soil moisture during tillage but it is exigentin time and energy, leaving very little residues on the surface, even when the plowing is trained. It can cause wind erosion (sandy soils) and water erosion (all soils) and the formation of a layer called the ploughpan. The discs plow can cause a smoothing in medium and heavy soils unless they are dry during tillage. The discs harrow (Offset) relatively requires little time and energy per tilled unit of area (Abrougui and Chehaibi, 2012). When crop residues are abundant, the device leaves enough debris in surface to prevent wind erosion and beneficial effects of reduced tillage under discs harrow (offset) appear.Indeed, the dry bulk density decreased from one measurement date to another for the studied tillage systems. At last date, the density values increased 
and approach those of the initial state but the lowest averages were still presented by reduced tillage system.

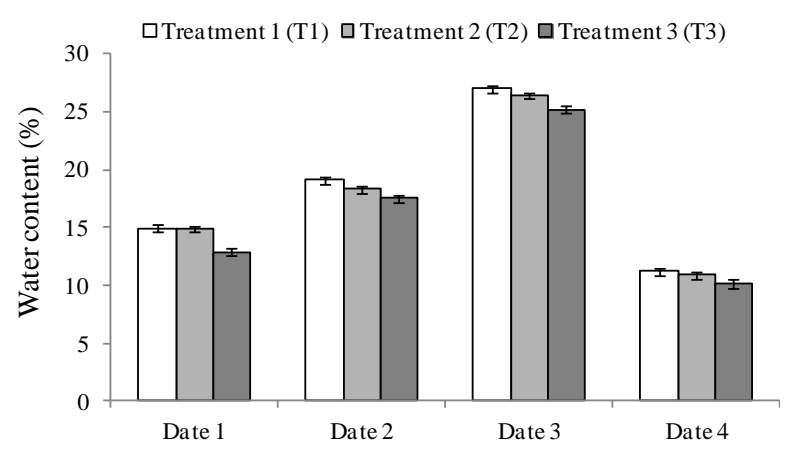

Figure 4 Evolution of soil water content as a function of measurement dates

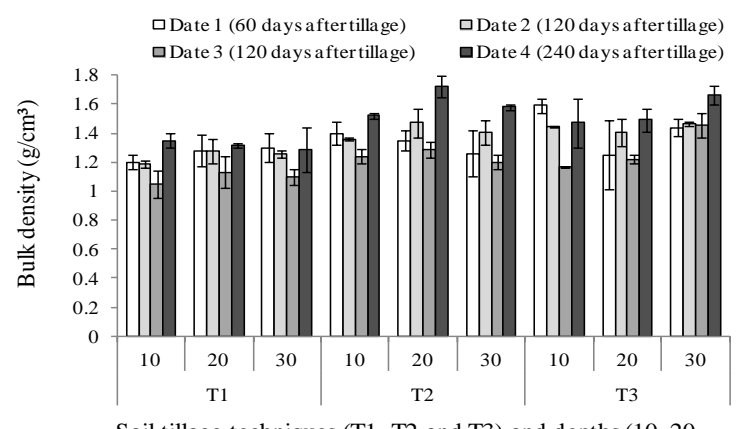

Soil tillage techniques (T1, T2 and T3) and depths (10, 20 and $30 \mathrm{~cm}$ )

Figure 5Effect of conventional (T3), medium (T2) and minimum (T1) tillage on soil bulk density

Table 4 ANOVA results for the bulk density data

\begin{tabular}{ccc}
\hline Source of variation & D.F. & M.S. \\
\hline Treatment & 3 & $8.881^{* *}$ \\
Date & 3 & $0.282^{* *}$ \\
Depth & 2 & $0.146^{* *}$ \\
Treatment*Date & 9 & $0.042^{* *}$ \\
Error & 96 & 0.011 \\
\hline
\end{tabular}

$* *$ : significant at the $5 \%$ level.

Table 5 Average values of bulk density

\begin{tabular}{cc}
\hline Treatment & Bulk density \\
\hline Initial state & $2.33 \mathrm{c}$ \\
T 1 & $1.21 \mathrm{a}$ \\
T 2 & $1.42 \mathrm{~b}$ \\
T 3 & $1.44 \mathrm{~b}$ \\
\hline
\end{tabular}

Statistical analyses of the data at $* \mathrm{P}<0.05$ showed significant effects of the treatment, date of measurement and depth on bulk density (Table 4). Average bulk density at $0-50 \mathrm{~cm}$ and for all measurement dates, differed for the different tillage systems. Different letters indicate different classes of bulk density (Table 5). ANOVA analysis does not show a significant difference between $\mathrm{T} 2$ and $\mathrm{T} 3$. The higher average corresponds to the initial state whereas the lowest occurs following minimum tillage (T1). Figure 6 shows that resistance to penetration was well correlated to bulk density with a correlation coefficient $\mathrm{R}^{2}=0.79$.

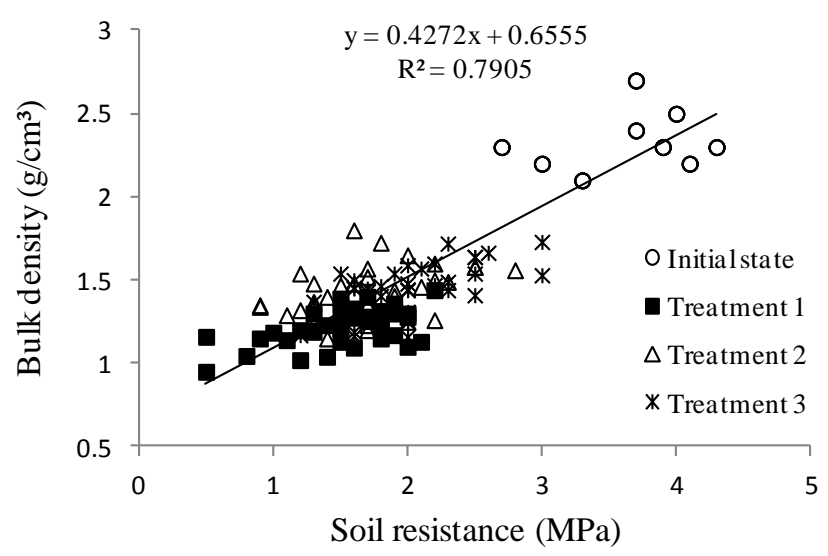

Figure 6 Correlation between bulk density and soil resistance to penetration

\subsection{Soilcrumbling index}

Average crumbling index (Figure 7) under different treatments compared for the three operations: (tillage, tillage + first tillage resumption and tillage + first + second tillage resumption), shows that clods percentage left in surface is higher for T3 compared to T1 and T2 treatments. Results showed that crumbling index increases with the number of operations performed for each treatment. Indeed, from only plowing to plowing plus first resumption, the crumbling index increases from 0.28 to 0.39 for $\mathrm{T} 3$ and from 0.31 to 0.42 for $\mathrm{T} 2$. Also, for $\mathrm{T} 1$ crumbling index increases from 0.35 to 0.48 from tillage to tillage plus first resumption.

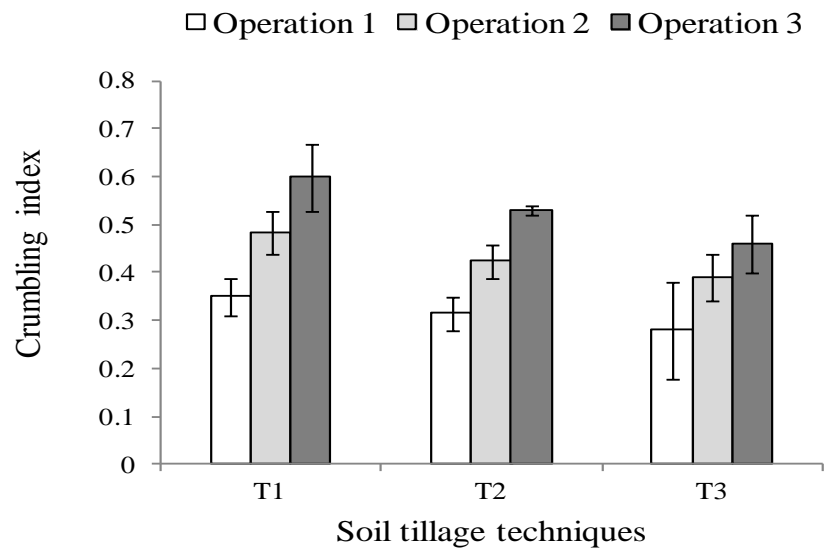

Figure 7 Effect of conventional (T3), medium (T2) and minimum (T1) tillage on soil crumbling index

These findings remain valid for the last operation (tillage + first + second resumption) where the crumbling index value reached $0.6,0.53$ and 0.46 for $\mathrm{T} 1, \mathrm{~T} 2$ and $\mathrm{T} 3$ respectively. The reduced or minimum tillage under discs harrow at a maximum depth of $10 \mathrm{~cm}$ (T1) is therefore characterized by the higher crumbling index compared to T2 and T3 for all operations. It appears that conventional deep tillage under moldboard plowing (T3) provides lowest superficial crumbling index.The instability of soil structure and the clods rate in soil surface were 
significantly greater under conventional tillage than reduced tillage system. Both reduced tillage and zero tillage increased soil stability with greater differences between systems in poorer structured soils. Averaging results from all experiments showed that structural instability was $70 \%$ higher in plowed soil (Alvarez and Steinbach, 2009). Soil tillage usually induces a reduction in aggregates size (McVayet al., 2006) and stability to wind erosion (Singh and Malhi, 2006) or water effects (Franzluebbers and Stuedemann, 2008) in relation to notill management. Differences in aggregate stability are very deep when no-till is compared with soil tilled by the moldboard plow (Hernanz et al.,2002; Martinez et al., 2008), and intermediate when it is compared to reduced tillage systems, like chisel tillage (Alvaro-Fuentes et al., 2008).

Statistical analyses of the data at $* \mathrm{P}<0.05$ show significant effects of the treatment and the date of measurement on soil crumbling index (Table 6). Analysis does not show a significant difference between $\mathrm{T} 2$ and $\mathrm{T} 3$. The higher average (Table 7) corresponds to T1 (minimum tillage) whereas the lowest occurs following T3 (conventional deep tillage).

Table 6 ANOVA results for the soil crumbling index

\begin{tabular}{ccc}
\hline Source of variation & D.F. & M.S. \\
\hline Treatment & 2 & $0.023^{*}$ \\
Date & 2 & $0.104^{* *}$ \\
Treatment*Date & 4 & $0.001 \mathrm{NS}$ \\
Error & 18 & 0.003 \\
\hline
\end{tabular}

$* *$ : significant at the $5 \%$ level.

Table 7 Average values of soil crumbling index

\begin{tabular}{cc}
\hline Treatment & Crumbling index \\
\hline T 1 & $0.47 \mathrm{~b}$ \\
T 2 & $0.42 \mathrm{a}$ \\
T 3 & $0.37 \mathrm{a}$ \\
\hline
\end{tabular}

\section{Conclusion}

The characterization of the soil resistance to penetration, the bulk density and the soil crumbling index give essential indications about soil quality and vulnerability in relation to degradation events mainly connected with environmental conditions and allow the prediction of the changes that can be expected following soil structural modifications induced by tillage systems,or following soil degradation due to compaction, formation of surface crusts, etc.The results of this study confirmed that conventional ploughing induced the more relevant modification of soil physical properties resulting in damage to soil structure. The negative aspects associated with this management system are the formation of surface crusts and ploughpan at the lower cultivation limit. The formation of the ploughpan, the increase of soil resistance to penetration and bulk density, the decrease of the crumbling index and water loss in the surface layer of conventionally tilled soil, may also hamper root growth. Minimum tillage could be a good alternative to conventional ploughing in Tunisian Sahel with medium texture soils. Future work should be focused on the study of the impact of tillage systems on soil biological activity and the promotion of research on productivity of some cultures under these tillage managements.

\section{References}

Abrougui K., Chehaibi S. \&Khelifi M. (2012a), Impact of mechanical aeration on the soil resistance to penetration and density of a grassy sward.J. Environ. Sci. Eng(USA). A1, 683687.

Dexter AR. (1988), Advances in characterization of soil structure. Soil Till. Res. 11, 199-238.

Manichon H. (1988), Compactage, décompactage et système de cultures. Compte Rendus de l'Académie d'Agriculture France. pp. 39-52.

Soane B.D. \& Van Ouwerkerk C. (1994), Soil compaction problems in word agriculture. Elseiver, Soil Compaction and Crop Production, Amsterdam. pp. 1-21.

Koolen AJ, (1994), Mechanics of soil compaction. Elseiver. Soil Compaction and Crop Production, Amsterdam. pp. 23-44.

Estrade J.R., Richard G., Boizard H., Boiffin J., Caneill J. \&Manichon H. (2000), Modelling structural changes in tilled topsoil over time as a function of cropping systems. Eur J Sol SCI. 51, 455-474.

Estrade J.R., Richard G., Caneill J., Boizard H., Coquet Y., Defossez P. \&Manichon H. (2004), Morphological characterisation of soil structure in tilled fields: from a diagnosis method to the modeling of structural changes over time. Soil Till. Res. 79, 33-49.

Pagliai M., Vignozzi N. \&Pellegrini S. (2004), Soil structure and the effect of management practices. Soil Till. Res. 79, 131-143.

Pagliai M., Vignozzi N. \&Pellegrini S. (1998), The quantification of soil degradation problems in relation to the impact of agricultural management practices. In: Proceedings of the 16th World Congress of Soil Science, 19-27 August, Montpellier.

Gicheru P., Gachene C., Mbuvi J. \&Marea E. (2004), Effects of soil management practices and tillage systems on surface soil water conservation and crust formation on a sandy loam in semi-arid Kenya. Soil Till. Res. 75, 173-184.

Courty MA.(1985), Morphology and genesis of soil surface crusts in semi arid conditions. In: Callebant F., D. Gabriels and M. DeBoodt. (Eds.), Assessment of Soil Surface Sealing and Crusting. Flader Research Centre for Soil Erosion and Soil Conservation. Ghent, Belgium. pp. 64-71.

FAO/UNESCO.(1997), Soil Map of the World.1, 5M.

Briggs SR., Ellis J. \&Twomlow SJ.(1998), Modern methods from traditional soil and water conservation technologies.In: Proceedings of the DFID Land Management Workshop Kabale, Uganda.

Billot JF. (1989). Pénétrométrie, choix des outils et dates de travail du sol.Pays Bas: Balkema, Rotterdam.

Vitlox O. \&Loyen S. (2002), Conséquences de la mécanisation sur la compaction du sol et l'infiltration de l'eau. Compte rendu de la journée d'étude: Erosion hydrique et coulées boueuses en Région Wallonne, pp. 45-58.

Allen RR. \& Musick JT. (1997), Furrow irrigation infiltration with multiple traffic and increased axle mass. ASAE. 13(1), 4953.

Abrougui K., Chehaibi S., Louvet JN., Hannachi C. \& Destain MF. (2012b),Soil Structure and the Effect of Tillage Systems.Bulletin UASVM Agriculture. 69, 11-16.

Keller T., Défossez P., Weisskopf P., Arvidsson J. \&G Richard. (2007), SoilFlex: A model for prediction of soil stresses and soil compaction due to agricultural field traffic including a synthesis of analytical approaches. Soil\& Tillage Research. 93 391-411. 
Yoro G. \& Godo G. (1990), Les méthodes de mesure de la densité apparente: analyse de la dispersion des résultats dans un horizon donné, Cah. ORSTOM, sér. Pédol. XXV, 423-429.

Lajoux P. (2003), Guide d'essais de terrain. Coordination des essais de terrain de matériel agricole.CUMA France, version $\mathrm{n}^{\circ} 1$.

Angers DA., Bissonnette N., Lègère A. \&Samson N. (1993), Microbial and biochemical changes induced by rotation and tillage in a soil under barley production.Can. J. SoilSci. 73, 3950.

CRAAQ. (2011), Centre de références en agriculture et agroalimentaire du Québec. Travail du sol: Impacts sur les propriétés du sol, les cultures et l'environnement. Guide des pratiques de conservation en grandes cultures.

Strudley M.W., Green TR. \&Ascough JC. (2008), Tillage effects on soil hydraulic properties in space and time: state of the science. Soil Till. Res. 99, 4-48.

Gomez GA., Singer MJ., Power RF. \&Horwath WR. (2002), Soil compaction effects on water status of ponderosa pine assessed through C13/C12 composition.Tree Physiol. 22, 459-467.

Ishaq M., Hassan A., Saeed M., Ibrahim M. \&Lal R. (2001), Subsoil compaction effects on crops in Panjab, Pakistan. Soil Till. Res. 59, 57-65.

Arachchi LP. (2009), Effect of deep ploughing on the water status of highly and less compacted soils for coconut (Cocosnucifera L.) production in Sri Lanka. Soil Till. Res. 103, 350-355.

Defossez P., Richard G., Boizard H. \& Sullivan MFC. (2003), Modeling change in soil compaction due to agricultural traffic as function of soil water content. Geoderma. 116, 89-105.
Abrougui K. \&Chehaibi S. (2012), Average fuel consumption of Japanese conventional tractor depending on its forward speed and engine speed. In: Second Tunisian Congress of Mechanics COTUME'2012, Sousse. pp. 19-21.

Alvarez R. \& Steinbach HS. (2009), A review of the effects of tillage systems on some soil physical properties, water content, nitrate availability and crops yield in the Argentine Pampas. Soil Till. Res. 104, 1-15.

McVay KA., Budde JA., Fabrizzi K., Mikha MM., Rice CW., Schlegel AJ., Peterson DE., Sweeney DW. \& Thompson C. (2006), Management effects on soil physical properties in long-term tillage studies in Kansas. Soil Sci. Soc. Am. J. 70 , 434-438.

Singh B. \&Malhi SS. (2006), Response of soil physical properties to tillage and residue management on two soils in a cool temperate environment. Soil Till. Res. 85, 143-153.

Franzluebbers A.J. \&Stuedemann JA. (2008), Soil physical responses to cattle grazing cover crops under conventional and no tillage in the Southern Piedmont USA. Soil Till. Res. 100, $141-153$.

Hernanz J.L., Lopez R., Navarrete L. \& Sanchez-Giron V. (2002), Long-term effects of tillage systems and rotations on soil structural stability and organic carbon stratification in semiarid central Spain. Soil Till. Res. 6, 129-141.

Martinez E., Fuentes JP., Silva P., Valle S. \& Acevedo E. (2008), Soil physical properties and wheat root growth as affected by no-tillage and conventional tillage systems in a Mediterranean environment of Chile. Soil Till. Res. 99, 232-244.

Alvaro-Fuentes J., Arrue JL., Gracia R. \& Lopez MV. (2008), Tillage and cropping intensification effects on soi aggregation: temporal dynamics and controlling factors under semiarid conditions. Geoderma. 145, 390-396. 